Published in final edited form in Molecular and Cellular Endocrinology, 460:181-188. at https://doi.org/10.1016/j.mce.2017.07.022

\title{
Vaspin suppresses cytokine-induced inflammation in 3T3-L1 adipocytes via inhibition of NFKB pathway
}

\author{
Konstanze Zieger $^{1 *}$, Juliane Weiner ${ }^{1,2^{*}}$, Kerstin Krause ${ }^{2}$, Maximilian Schwarz ${ }^{1}$, Martin Kohn', \\ Michael Stumvoll², Matthias Blüher ${ }^{2,3}$ and John T. Heiker 1, 2,3 \\ ${ }^{1}$ Institute of Biochemistry, Faculty of Biosciences, Pharmacy and Psychology, University of Leipzig, \\ Leipzig, Germany \\ ${ }^{2}$ Divisions of Endocrinology and Nephrology, University of Leipzig, Leipzig, Germany. \\ ${ }^{3}$ IFB Adiposity Diseases, University of Leipzig, Leipzig, Germany \\ *contributed equally
}

To whom correspondence should be addressed: John T. Heiker, Institute of Biochemistry, University of Leipzig, Brüderstrasse 34, 04103 Leipzig, Germany,

Tel.: +49-341-9736990, Fax: +49-341-9736909, E-mail: jheiker@uni-leipzig.de 


\begin{abstract}
Vaspin expression is increased in white adipose tissue (WAT) of diet-induced obese mice and rats and is supposed to compensate HFD-induced inflammatory processes and insulin resistance in adipose tissue by counteracting pro-inflammatory gene expression in obesity. Multiple studies have also demonstrated strong anti-inflammatory effects in vascular and skin cells. Here, we used vaspin treated 3T3-L1 murine adipocytes as well as 3T3-L1 cells with stable vaspin expression to investigate the effect of exogenous and endogenous vaspin on inflammatory processes and insulin signaling in adipocytes.

Our stably transfected cells secreted significant amounts of vaspin which was in the physiological range of $\sim 0.5 \mathrm{ng} / \mathrm{ml}$ in cell supernatants. Adipocyte differentiation was not affected by vaspin as expression of adipogenic marker genes as well as lipid accumulation after full differentiation was similar to control cells. We found that IL-1 $\beta$ induced expression and secretion of pro-inflammatory cytokines, such as IL-6, MCP1 and TNF $\alpha$ was significantly blunted in vaspin expressing 3T3-L1 cells. Treatment of 3T3-L1 cells with exogenous vaspin resulted in reduced cytokine-induced activation of the intracellular and pro-inflammatory NFKB signaling cascades (IKK $\alpha / \beta, \mathrm{I} \kappa \mathrm{B}$ and $\mathrm{NF} \kappa \mathrm{B})$. Moreover, endogenous vaspin positively affected insulin signaling by increasing insulin-stimulated phosphorylation of the key mediator protein kinase B (AKT).

Together, we demonstrate anti-inflammatory effects of vaspin in 3T3-L1 adipocytes as well as increased insulin signaling by endogenous expression or exogenous treatment. The results provide evidence for potent anti-inflammatory action of vaspin not only in vascular cells but also in adipose tissue.
\end{abstract}

Keywords. adipose tissue, adipokine, inflammation, insulin sensitivity, obesity, serpin, vaspin

Abbreviations: $A T$, adipose tissue; FFA, free fatty acids 


\section{Introduction}

Chronic low-grade adipose tissue (AT) inflammation and increased AT macrophage infiltration are main characteristics of AT dysfunction in obesity [1,2]. Secretion of proinflammatory cytokines by both adipocytes [3-5] and AT macrophages [6] contributes to the development of insulin resistance and atherosclerosis [7,8]. Tumor necrosis factor (TNF)- $\alpha$ and interleukin IL6 represent prominent pro-inflammatory cytokines [3,9] and adiponectin the most prominent anti-inflammatory adipocytokine [10]. Vaspin (visceral adipose tissue-derived serine protease inhibitor, SERPINA12) is a beneficial adipokine counteracting insulin-resistance and inflammatory processes in obese mice [11-13]. Vaspin treatment or transgenic overexpression of vaspin in AT of obese and insulin resistant mice ameliorated expression of inflammatory genes in vivo $[12,13]$. Specific anti-inflammatory [14], anti-migratory [15] and anti-apoptotic $[16,17]$ properties have been demonstrated in vascular endothelial and smooth muscle cells as well as in skin keratinocytes [18]. Previous studies have also reported vaspin to induce intracellular signaling e.g. via AKT kinase in pre-osteoblast or vascular cells $[16,19]$ and to furthermore promote insulin signaling by enhancing AKT activation in 3T3-L1 cells [20].

Albeit being identified as an adipokine, little is known about vaspins' regulatory/modulatory role in obesity-associated inflammation of adipose tissue and adipocytes. Here, we established a stably transfected 3T3-L1 pre-adipocyte cell line to investigate vaspin effects on IL-1 $\beta$ stimulated secretion of proinflammatory cytokines and NF-kB signaling in adipocytes.

\section{Materials and Methods}

\subsection{Cell culture}

Transfection procedure: For transfections, 3T3-L1 cells were split into 6-well plates $\left(2 \times 10^{5} /\right.$ well) and grown for $48 \mathrm{~h}$. Cells were transfected with pcDNA3.1 vector containing the cDNA of the full length vaspin coding sequence (a kind gift of Dr. Jana Breitfeld) using Gene Jammer (Agilent technologies, Santa Clara, CA, USA) according to the manufacturer's protocol. To isolate 3T3-L1 cells carrying either the vaspin plasmid (vaspin_3T3-L1) or the empty vector (vector_3T3-L1), cell clones were selected by geneticin resistance selection during 15 days (400 $\mu \mathrm{g} / \mathrm{ml}$ geneticin). A mixed cell clone was then generated consisting of at least 10 single clones.

Cultivation: Cell culture experiments were performed using native 3T3-L1 cells and stably transfected cell lines. Cells were grown at $37^{\circ} \mathrm{C}$ and $5 \% \mathrm{CO}_{2}$ at sub-confluence in Dulbecco's Modified Eagle Medium (DMEM, Gibco, Thermo Fisher, Waltham, Massachusetts, USA) containing 10\% FBS (culture medium). Adipogenesis was induced $48 \mathrm{~h}$ post-confluence (day 2) 
by cultivation in culture medium supplemented with $1 \mu \mathrm{M}$ insulin, $0.5 \mathrm{mM}$ IBMX and $0.4 \mu \mathrm{g} / \mathrm{ml}$ dexamethasone for 2 days. After another 2 days in medium containing $1 \mu \mathrm{M}$ insulin, medium was replaced to DMEM/10\% FBS until day 10. To analyze gene expression during adipogenesis, cells were either harvested when confluent (day 0), during (day 6) or after full differentiation (day 10). To evaluate influences of external vaspin treatment, $200 \mathrm{ng} / \mathrm{ml}$ recombinant human vaspin (derived from HEK293 cells, PeproTech, Inc., Rocky Hill, NJ, USA) was added to the medium for the entire adipogenic differentiation (day 2-10).

Stimulation assays: All stimulation assays were performed with serum-starved cells (16h) at day 10 of differentiation. To analyze cytokine-induced inflammation, cells were incubated with $10 \mathrm{ng} / \mathrm{ml} \mathrm{IL}-1 \beta$ for $15 \mathrm{~min}$ or $24 \mathrm{~h}$, respectively. $0.1 \%$ BSA was used as vehicle control. Insulin stimulation was done adding aqua dest (control) or $100 \mathrm{nM}$ insulin to serum-starved cells for $10 \mathrm{~min}$. Depending on the experimental set up, cells were harvested at indicated time points. Supernatants were collected, centrifuged $\left(4^{\circ} \mathrm{C}, 11000 \mathrm{rpm}, 10 \mathrm{~min}\right)$, aliquoted and subsequently stored at $-30^{\circ} \mathrm{C}$. Cells were washed twice with PBS and immediately frozen at $-80^{\circ} \mathrm{C}$ until further use.

\subsection{AdipoRed assay}

Quantitative measurement: At day 0,6 and 10 of differentiation, cells were washed twice with PBS and incubated with AdipoRed reagent (AdipoRed ${ }^{\mathrm{TM}}$ Assay Reagent, Lonza Walkersville, Inc) in PBS at room temperature. After $15 \mathrm{~min}$, the fluorescence signal was measured (excitation: $485 \mathrm{~nm}$; emission: $572 \mathrm{~nm}$ ) using a plate reader (Mithras LB 940).

Fluorescence microscopy: Simultaneously, additional cells were incubated with the AdipoRed reagent and subjected to fluorescence microscopy. Microscopic examination was performed using an Axio Observer Microscope (Carl Zeiss, Jena, Germany). Images were obtained using ZEN2012 software (Carl Zeiss, Germany).

\subsection{RNA isolation, cDNA synthesis and qPCR}

Total RNA was isolated and purified using InviTrap ${ }^{\circledR}$ Spin Tissue RNA Mini Kit (Stratec Biomedical, Birkenfeld, Germany) as specified by the manufacturer. For quantification of gene expression, $1 \mu \mathrm{g}$ RNA was transverse transcribed using random hexamer primers (Promega, Madison, Wisconsin, USA) and MLV Reverse Transcriptase (Promega). qPCR was performed using the LightCycler ${ }^{\circledR}$ DNA Master SYBR Green I Kit (Roche, Mannheim, Germany) on a LightCycler480 system (Roche). Gene expression data were calculated by the $\Delta \Delta \mathrm{Ct}$-method 
and normalized to murine NoNo. Oligonucleotides were purchased from MWG Biotech (Ebersberg, Germany). The following gene-specific primers and sequences were used:

Table 1. Primer sequences used for qPCR analysis.

\begin{tabular}{|l|l|l|}
\hline Primer & forward & reverse \\
\hline NoNo $(53610)$ & TGCTCCTGTGCCACCTGGTACTC & CCGGAGCTGGACGGTTGAATGC \\
\hline Fabp4 $(11770)$ & AACACCGAGATTTCCTTCAA & AGTCACGCCTTTCATAACACA \\
\hline Il-6 $(16193)$ & ACCTGGAGTACATGAAGAACA & TTGGAAATTGGGGTAGGAAG \\
\hline Mcpl $(20296)$ & GCCCCACTCACCTGCTGCTACT & CCTGCTGCTGGTGATCCTCTTGT \\
\hline Ppary $(19016)$ & CGTGAAGCCCATCGAGGACATC & TGGAGCAGGGGGTGAAG \\
\hline $\begin{array}{l}\text { SERPINA12 } \\
(145264)\end{array}$ & AGGGCTTCCATTACATCATCCA & AACAGCGTGTTCCCAATGCT \\
\hline
\end{tabular}

The NCBI Gene ID is given in brackets.

\subsection{ELISA analyses}

Determination of vaspin, IL-6 and TNF $\alpha$ within cell supernatants was done by enzyme-linked immunosorbent assay (ELISA) using commercially available kits according to manufactures instructions. The following kits were used: Human Vaspin (AG-45A-0017YEK, Adipogen, San Diego, CA, USA), murine IL-6 ELISA developmental kit (Cat\#900-K50, PeproTech, Hamburg, Germany) and TNF $\alpha$ ELISA developmental kit (Cat\#900-K54, PeproTech).

\subsection{Western blot analysis}

Total protein was isolated with RIPA buffer $(150 \mathrm{mM} \mathrm{NaCl}, 10 \mathrm{mM}$ Tris $\mathrm{pH} 7.2,0.1 \%$ SDS, $1 \%$ Triton X-100, 1\% sodiumdeoxycholate and 5mM EDTA) complemented with protease and phosphatase inhibitors (Protease and Phosphatase Inhibitor Mini Tablets, Pierce Protein Biology, Thermo Fisher Scientific, Waltham, Massachusetts, USA), incubated for 45 min at 4 ${ }^{\circ} \mathrm{C}$ and centrifuged $\left(4^{\circ} \mathrm{C}, 13.000 \mathrm{rpm}, 20 \mathrm{~min}\right)$. Isolation of nuclear and cytoplasmic protein fractions was achieved by centrifugation steps. Briefly, cell cultures were harvested and lysed in homogenization buffer (10mM HEPES pH7.5, 1.5mM MgCl2, 10mM KCl, 0.5mM DTT, supplemented with protease and phosphatase inhibitor cocktail). Lysates were homogenized by passing through a needle and separated by centrifugation at $1000 \mathrm{~g}$ at $4^{\circ} \mathrm{C}$ for $15 \mathrm{~min}$. The obtained cell pellet was re-suspended in homogenization buffer (nuclear fraction) while the supernatant was collected and centrifuged at $100,000 \mathrm{xg}$ at $4^{\circ} \mathrm{C}$ for $60 \mathrm{~min}$ and the clear phase was used for analyses (cytoplasmatic fraction). Protein concentration of clear lysates was 
determined using BCA assay kit (Pierce, Waltham, USA) according to the manufacturer's instructions. Equal amounts of protein $(10-30 \mu \mathrm{g})$ were resolved by SDS-Page (12\%) and transferred to a nitrocellulose membrane by tank blot method. Membranes were blocked with $3 \%$ BSA and incubated with primary antibodies at $4{ }^{\circ} \mathrm{C}$ overnight. The following antibodies were used: phospho-NFkB (CST \#3033), NFкB (MW 65kDa; CST \#8242) phospho-IKK $\alpha / \beta$ (CST \#2697), IKK $\alpha / \beta$ (MW 85/87kDa; CST \#8943), phospho-IкB $\alpha$ (CST \#2859, 1:1000), IкB $\alpha$ (MW 40kDa; CST \#4814), phospho-AKT (CST \#4060), AKT (MW 60 kDa; CST \#4691) and $\beta$-actin (MW 42kDa; ab8227, Sigma, St. Louis, Missouri, USA). All primary antibodies were used with a 1:1000 dilution. Afterwards, membranes were washed and incubated with appropriate horseradish peroxidase-conjugated secondary antibodies (CST) for $1 \mathrm{~h}$ at room temperature.

\subsection{Statistical analyses}

All values were shown as mean \pm SEM. Statistical analyses were performed by GraphPad Prism 7.0 software (GraphPad, San Diego, Ca, USA) using two-tailed Student's t-test for comparison of two groups. Comparison of multiple groups was assessed using one-way ANOVA followed by Bonferroni's post-hoc test. P-values less or equal to 0.05 were considered to be statistically significant.

\section{Results}

\subsection{Generation of a vaspin overexpressing 3T3-L1 adipocyte cell line}

To evaluate the effects of endogenous vaspin expression on adipose tissue biology in vitro, we generated a 3T3-L1 cell line stably overexpressing human vaspin based on the well-established murine 3T3-L1 pre-adipose cell model [21]. We first investigated vaspin expression and secretion in vaspin_3T3-L1 cells in comparison to native and vector transfected 3T3-L1 cells after full adipogenic differentiation. Both, vaspin mRNA expression as well as secretion, were significantly increased (>200-fold) in vaspin_3T3-L1 while we detected only marginal levels in native 3T3-L1 and empty vector control cells (Figure 1A, B). Secreted vaspin reached physiological concentrations of $\sim 0.5 \mathrm{ng} / \mathrm{ml}$ [22] in cell supernatants after $48 \mathrm{~h}$ of cultivation.

\subsection{Effects of vaspin on differentiation in 3T3-L1 adipocytes}

Exogenous vaspin treatment was reported to slightly promote adipogenic differentiation of 3T3L1 pre-adipocyte using vaspin concentrations of up to $200 \mathrm{ng} / \mathrm{ml}$ [20]. We analyzed the accumulation of lipid droplets in vaspin_3T3-L1 and vector_3T3L 1 cell clones as well as in 
native and vaspin-treated 3T3-L1 cells. Cultures were examined prior (day 0), during (day 6) and after full adipogenic differentiation (day 10). Microscopic evaluation revealed the absence of lipid droplets in undifferentiated cells (day 0). In the course of adipogenesis, all cells started to accumulate lipids and large lipid droplets of similar size and number (day 10) were observed regardless of endogenous or exogenous vaspin treatment (Figure 2A). This was also reflected in the quantitative analyses of intracellular lipid content, showing similar levels in all cells independent of treatment (Figure 2B). Gene expression of adipocyte-specific marker genes Ppary and Fabp4 showed a differentiation-dependent increase with comparable levels in native 3T3-L1 cells and vaspin overexpressing cells (Figure 2C, D).

\subsection{Effects of vaspin on insulin stimulated AKT phosphorylation in differentiated adipocytes}

In vivo and in vitro studies demonstrated vaspin-mediated phosphorylation and consequently activation of the serine-threonine protein kinase AKT which regulates a multitude of processes involved in metabolism, proliferation or cell growth [12,16,20]. Analyzing the basal phosphorylation level of AKT in native 3T3-L1, vaspin_3T3-L1 and vector_3T3-L1 cells we found no differences in AKT phosphorylation (Figure 3A, B). However, insulin-induced phosphorylation of AKT was significantly enhanced in vaspin expressing 3T3-L1 cells compared to native and empty vector control cells (Figure 3 ), indicating enhanced activation of the AKT-pathway by endogenous vaspin.

\subsection{Effects of vaspin on the chemokine induced inflammatory response in differentiated adipocytes}

Vaspin has been shown to exert anti-inflammatory and anti-atherogenic properties in endothelial and smooth muscle cells [14,17,23-25]. Liu et al. reported decreased Il-6 mRNA levels after exogenous vaspin treatment of 3T3-L1 cells [20]. Here, we evaluated vaspin effects on cytokine-induced inflammatory response in adipocytes. Stimulation of native 3T3-L1 cells with IL-1 $\beta$ induced significant secretion of the pro-inflammatory cytokines IL- 6 and TNF $\alpha$ into the cell supernatant (Figure 4A, B). In contrast, this inflammatory response was significantly blunted in vaspin_3T3-L1 with nearly no increases of IL-6 and TNFa in cell supernatants (Figure 4A, B). These results were further confirmed by gene expression analyses. Il-6 and monocyte chemotactic protein 1 (Mcpl) mRNA expression were significantly lower in IL-1 $\beta$ treated vaspin_3T3-L1 clones compared to native 3T3-L1 cells (Figure 4C, D). 


\subsection{Vaspin inhibits IL-1 $\beta$-induced NFKB signaling}

Next, we asked about underlying molecular mechanisms mediating the anti-inflammatory effects of vaspin. The NFKB signaling pathway is a key regulator of MCP-1 and IL-6 expression and we examined vaspin-mediated effects on NFkB signaling in 3T3-L1 cells. Therefore, native 3T3-L1 cells were differentiated in the absence or presence of $200 \mathrm{ng} / \mathrm{ml}$ vaspin and the

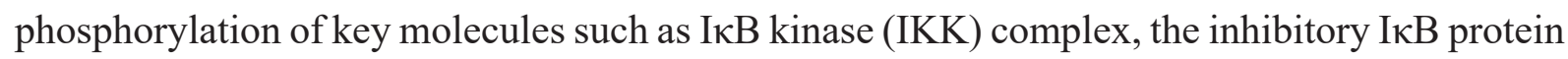
and NFאB in response to IL- $1 \beta$ were investigated. Incubation with IL-1 $\beta$ lead to a significant increase in IKK $\alpha / \beta$ phosphorylation exclusively in untreated 3T3-L1 cells while vaspin treatment prevented marked activation of the kinase complex (Figure 5A, B). Accordingly, the downstream target I $\kappa$ B was predominantly phosphorylated in IL-1 $\beta$-stimulated 3T3-L1 controls and only marginally in vaspin-treated cultures (Figure 5A, B). In line with the phosphorylationmediated degradation of $\mathrm{I} \kappa \mathrm{B}$, we observed enhanced phosphorylation and activation of cytoplasmic NFאB solely in control 3T3-L1 cells without vaspin pretreatment (Figure 5A, B).

\section{Discussion}

Excessive fat accumulation provokes the emergence of a low-grade inflammatory state within adipose tissue. This is accompanied by enhanced expression of pro-inflammatory genes and increased infiltration of immune cells, i.e. neutrophils and macrophages, further exaggerating the inflammatory process and contributing to systemic inflammation [26,27]. The local macrophages but also the AT itself release substantial amounts of pro-inflammatory cytokines that contribute to further increase immune cell infiltration and cytokine release that subsequently contributes to impaired hepatic and skeletal glucose homeostasis and finally systemic insulin resistance $[3,6,7]$.

The serpin vaspin has been previously shown to exert potent anti-inflammatory effects in various endothelial, osteoblast and skin cells (reviewed in [28]) and the aim of this study was to investigate vaspin effects on cytokine induced inflammatory response in isolated adipocytes. Vaspin overexpression in isolated 3T3-L1 adipocytes led to the inhibition of the proinflammatory IL-1 $\beta$ pathway and we observed a significant reduction of major proinflammatory cytokines IL- 6 and TNF $\alpha$ after IL- $1 \beta$ treatment. Also, IL-1 $\beta$ induced gene expression of Il-6 and Mcpl was markedly diminished in vaspin_3T3-L1 cells. The transcription factor $\mathrm{NF \kappa B}$ promotes the immune responses by initiating gene expression of inflammatory genes such as TNF $\alpha$, IL-6 and MCP1. We proposed a vaspin-mediated regulation of the NFkB signaling cascade as an underlying mechanism for anti-inflammatory effects in adipocytes. Using a luciferase reporter systems, pre-treatment with vaspin was previously 
shown to suppress TNF $\alpha$-mediated activation of NFאB in endothelial EA.hy926 [24] and HAEC [14] cells. Also, vaspin treatment of smooth muscle cells blunted TNF $\alpha$-induced

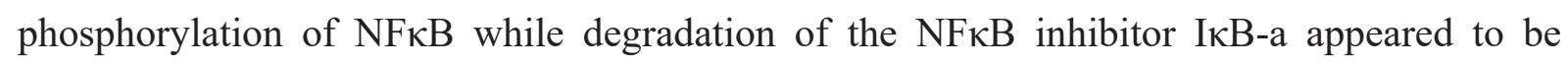
unaffected in this cell line [29]. Here, treatment of isolated and fully differentiated adipocytes with vaspin caused a marked reduction in IL-1 $\beta$-induced NFKB signaling already at the level of IKK $\beta$ and I $\mathrm{KB}$ phosphorylation. Thus the anti-inflammatory effects of vaspin in adipocytes are likely mediated by inhibition of the NFkB signaling pathway and its downstream molecules. Inflammation induced AT dysfunction furthermore results in inadequate release and thus enhanced circulating levels of free fatty acids (FFA) known to contribute to insulin resistance by interfering with insulin signaling [30]. The impairment of insulin signaling, finally resulting in insulin resistance, plays a crucial role in the pathogenesis of metabolic disorders and type 2 diabetes.

The phosphatidylinositol 3-kinase (PI3)/AKT pathway is a key signaling axis regulating various critical intracellular processes such as cell survival, proliferation and differentiation [31]. AKT is also a key signaling hub for insulin-induced glucose uptake into liver, skeletal muscle and adipose tissue [32]. The enzymatic activity of AKT is diminished under obese conditions due to increased activation of stress kinases such as AMP-activated protein kinase (AMPK) or IKK and subsequent phosphorylation of the insulin receptor and insulin receptor substrate 1 (IRS-1) and inhibition of IRS-mediated AKT activation [33-35]. Previous studies have reported that exogenous vaspin can induce intracellular signaling cascades and also the PI3/AKT pathway in different cell types, such as MC3T3-E1 preosteoblasts and vascular endothelial cells $[16,19]$. Vaspin was also reported to promote insulin signaling by enhancing the phosphorylation of AKT in the early differentiation phase of 3T3-L1 adipocytes [20]. In our studies, endogenous overexpression of vaspin had no basal effect on AKT phosphorylation but significantly increased insulin-stimulated activation of AKT. These effects of vaspin on insulin signaling are further confirmed by in vivo studies, as transgenic overexpression of vaspin in AT of mice enhanced hepatic phosphorylation of AKT [12]. In obese ICR mice, vaspin normalized expression of insulin-resistance associated genes such as Glut4, Leptin, and Tnf- $\alpha$ in white adipose depots [13]. Also in endothelial cells, vaspin was shown to prevent FFA-induced apoptosis by restoring the capacity to activate insulin signaling in HAEC cells [16].

Liu et al. also reported an increased gene expression of adipogenic genes (Fabp4, Ppar $\gamma$ ) together with apparently smaller lipid droplets after incubation of 3T3-L1 adipocytes with exogenous vaspin, which may indicate a differentiation-promoting effect of vaspin on adipocytes [20]. However, endogenous vaspin overexpression as well as external treatment of 9 
3T3-L1 cells with vaspin had no influence on differentiation or lipid incorporation in the adipocytes used in our study. There is also conflicting data on the vice-versa effect of adipogenesis on vaspin expression. We and others have shown, that vaspin expression in 3T3L1 cells was unchanged before and after differentiation [36,37], while others reported significant increases in vaspin gene and protein expression during differentiation of 3T3-L1 cells [38]. Notably, a recent paper has highlighted the great variability of the adipogenic potential of compounds and proteins in different adipocyte cell lines, also depending on the source of the cell line (distributer) and on the differentiation protocol used and thus has demonstrated the difficulties when comparing effects on differentiation even when using the same adipocyte cell lines [39].

Together, we here investigated the effects of the adipokine vaspin on fully differentiated murine adipocytes to elucidate if and by which mechanisms vaspin may counteract inflammatory processes in adipocytes and subsequently obesity-induced low-grade inflammation in AT. Our findings demonstrate that vaspin attenuates IL- $1 \beta$ induced pro-inflammatory cytokine response via inhibition of the $\mathrm{NF \kappa B}$ signaling pathway in isolated adipocytes. While vaspin overexpression had no effects on adipogenesis and adipocyte differentiation, vaspinoverexpressing adipocytes exhibited increased AKT phosphorylation upon insulin stimulation. A reduction of adipocyte derived pro-inflammatory cytokines, such as IL-6 [40], may be especially beneficial to counteract adipose tissue and systemic low-grade chronic inflammation associated with the metabolic syndrome. We conclude that vaspin contributes to counteract inflammation in adipocytes, potentially by inhibiting proteases that are involved in the activation of pro-inflammatory cytokines. Kallikrein 7 (KLK7) as a protease inhibited by vaspin [11] may be one example, as various pro-inflammatory proteins such as IL-1 $\beta$ [41], chemerin [42], midkine [43] or MMP9 [44] have been shown to be activated or cleaved by KLK7. 


\section{Author contributions}

KZ and JW conceived the study, designed and conducted experiments and wrote the manuscript. KK and JW generated vaspin expressing 3T3-L1 cell clones. MS and MK conducted experiments. MS and MB reviewed the manuscript and contributed to discussion. JTH interpreted and analyzed data, edited the manuscript and supervised the project.

Acknowledgements - We thank Dr. Karin Mörl and Dr. Peter Kovacs for valuable comments on the manuscript. The vaspin expression plasmid was kindly provided by Dr. Jana Breitfeld. Funding: This work was supported by the European Union and the Free State of Saxony (JTH), by the Formel1 Nachwuchsförderung of the Medical Faculty of the University of Leipzig (JTH, KK), by grants of the Deutsche Forschungsgemeinschaft SFB1052 "Obesity Mechanisms" (C1 MS, B1 MB, C7 JTH) and KR 4258/1-1 (KK) and by the DDG/German Diabetes Association (KK and JW). IFB AdiposityDiseases is supported by the German Federal Ministry of Education and Research (BMBF, FKZ: 01EO1501).

Disclosure statement: The authors have no conflicts of interest to declare. 


\section{References}

[1] Bluher, M., 2009. Adipose tissue dysfunction in obesity. Exp. Clin. Endocrinol. Diabetes. 117, 241-250.

[2] Hajer, G.R., van Haeften, T.W., Visseren, F.L.J., 2008. Adipose tissue dysfunction in obesity, diabetes, and vascular diseases. Eur. Heart J. 29, 2959-2971.

[3] Hotamisligil, G.S., Shargill, N.S. and Spiegelman, B.M., 1993. Adipose Expression of Tumor-Necrosis-Factor-Alpha - Direct Role in Obesity-Linked Insulin Resistance. Science. 259, 87-91.

[4] Sartipy, P., Loskutoff, D.J., 2003. Monocyte chemoattractant protein 1 in obesity and insulin resistance, Proc. Natl. Acad. Sci. U.S.A. 100, 7265-7270.

[5] Fried, S.K., Bunkin, D.A., Greenberg, A.S., 1998. Omental and subcutaneous adipose tissues of obese subjects release interleukin-6: Depot difference and regulation by glucocorticoid. J. Clin. Endocrinol. Metab. 83, 847-850.

[6] Weisberg, S.P., McCann, D., Desai, M., Rosenbaum, M., Leibel, R.L., Ferrante, A.W., 2003. Obesity is associated with macrophage accumulation in adipose tissue. J. Clin. Invest. 112, 1796-1808.

[7] Xu, H.Y., Barnes, G.T., Yang, Q., Tan, Q., Yang, D.S., Chou, C.J., Sole, J., Nichols, A., Ross, J.S., Tartaglia, L.A., Chen, H., 2003. Chronic inflammation in fat plays a crucial role in the development of obesity-related insulin resistance. J. Clin. Invest. 112, 1821-1830.

[8] Ohman, M.K., Shen, Y., Obimba, C.I., Wright, A.P., Warnock, M., Lawrence, D.A., Eitzman, D.T., 2008. Visceral adipose tissue inflammation accelerates atherosclerosis in apolipoprotein E-deficient mice. Circulation. 117, 798-805.

[9] Kern, P.A., Ranganathan, S., Li, C., Wood, L., Ranganathan, G., 2001. Adipose tissue tumor necrosis factor and interleukin-6 expression in human obesity and insulin resistance. Am. J. Physiol. Endocrinol. Metab. 280, 745-751.

[10] Ajuwon, K.M., Spurlock, M.E., 2005. Adiponectin inhibits LPS-induced NF-kappaB activation and IL-6 production and increases PPARgamma2 expression in adipocytes. Am. J. Physiol. Regul. Integr. Comp. Physiol. 288, 1220-1225.

[11] Heiker, J.T., Kloting, N., Kovacs, P., Kuettner, E.B., Strater, N., Schultz, S., Kern, M., Stumvoll, M., Bluher, M., Beck-Sickinger, A.G., 2013. Vaspin inhibits kallikrein 7 by serpin mechanism. Cell. Mol. Life Sci. 70, 2569-2583.

[12] Nakatsuka, A., Wada, J., Iseda, I., Teshigawara, S., Higashio, K., Murakami, K., Kanzaki, M., Inoue, K., Terami, T., Katayama, A., Hida, K., Eguchi, J., Horiguchi, C.S., Ogawa, D., Matsuki, Y., Hiramatsu, R., Yagita, H., Kakuta, S., Iwakura, Y., Makino, H., 2012. Vaspin Is an Adipokine Ameliorating ER Stress in Obesity as a Ligand for Cell-Surface GRP78/MTJ-1 Complex. Diabetes. 61, 2823-2832.

[13] Hida, K., Wada, J., Eguchi, J., Zhang, H., Baba, M., Seida, A., Hashimoto, I., Okada, T., Yasuhara, A., Nakatsuka, A., Shikata, K., Hourai, S., Futami, J., Watanabe, E., Matsuki, Y., Hiramatsu, R., Akagi, S., Makino, H., Kanwar, Y.S., 2005. Visceral adipose tissue-derived serine protease inhibitor: a unique insulin-sensitizing adipocytokine in obesity. Proc. Natl. Acad. Sci. U.S.A. 102, 10610-10615.

[14] Jung, C.H., Lee, M.J., Kang, Y.M., La Lee, Y., Yoon, H.K., Kang, S.W., Lee, W.J., Park, J.Y., 2014. Vaspin inhibits cytokine-induced nuclear factor-kappa B activation and adhesion molecule expression via AMP-activated protein kinase activation in vascular endothelial cells. Cardiovasc. Diabetol. 13, 41.

[15] Phalitakul, S., Okada, M., Hara, Y., Yamawaki, H., 2012. A novel adipocytokine, vaspin inhibits platelet-derived growth factor-BB-induced migration of vascular smooth muscle cells. Biochem. Biophys. Res. Com. 423, 844-849. 
[16] Jung, C.H., Lee, W.J., Hwang, J.Y., Seol, S.M., Kim, Y.M., Lee, Y.L., Park, J.Y., 2011. Vaspin protects vascular endothelial cells against free fatty acid-induced apoptosis through a phosphatidylinositol 3-kinase/Akt pathway. Biochem. Biophys. Res. Com. 413, 264-269.

[17] Nakatsuka, A., Wada, J., Iseda, I., Teshigawara, S., Higashio, K., Murakami, K., Kanzaki, M., Inoue, K., Terami, T., Katayama, A., Hida, K., Eguchi, J., Ogawa, D., Matsuki, Y., Hiramatsu, R., Yagita, H., Kakuta, S., Iwakura, Y., Makino, H., 2013. Visceral Adipose Tissue-derived Serine Proteinase Inhibitor Inhibits Apoptosis of Endothelial Cells as a Ligand for the Cell-Surface GRP78/Voltage-dependent Anion Channel Complex. Circ. Res. 112, 771780 .

[18] Saalbach, A., Tremel, J., Herbert, D., Schwede, K., Wandel, E., Schirmer, C., Anderegg, U., Beck-Sickinger, A.G., Heiker, J.T., Schultz, S., Magin, T., Simon, J.C., 2016. AntiInflammatory Action of Keratinocyte-Derived Vaspin Relevance for the Pathogenesis of Psoriasis. Am. J. Pathol. 186, 639-651.

[19] Liu, Y., Xu, F., Pei, H.X., Zhu, X., Lin, X., Song, C.Y., Liang, Q.H., Liao, E.Y., Yuan, L.Q., 2016. Vaspin regulates the osteogenic differentiation of MC3T3-E1 through the PI3KAkt/miR-34c loop. Sci. Rep. 6, 25578.

[20] Liu, P., Li, G.L., Wu, J., Zhou, X., Wang, L.P., Han, W.Q., Lv, Y., Sun, C.F., 2015. Vaspin promotes 3T3-L1 preadipocyte differentiation. Exp. Biol. Med. 240, 1520-1527.

[21] Green, H., Kehinde, O., 1975. An established preadipose cell line and its differentiation in culture. II. Factors affecting the adipose conversion. Cell. 5, 19-27.

[22] Youn, B.S., Kloting, N., Kratzsch, J., Lee, N., Park, J.W., Song, E.S., Ruschke, K., Oberbach, A., Fasshauer, M., Stumvoll, M., Bluher, M., 2008. Serum vaspin concentrations in human obesity and type 2 diabetes. Diabetes. 57, 372-377.

[23] Li, H.L., Peng, W.H., Zhuang, J.H., Lu, Y.Y., Jian, W.X., Wei, Y.D., Li, W.M., Xu, Y.W., 2013. Vaspin attenuates high glucose-induced vascular smooth muscle cells proliferation and chemokinesis by inhibiting the MAPK, PI3K/Akt, and NF-kappa B signaling pathways. Atherosclerosis. 228, 61-68.

[24] Liu, S.W., Dong, Y.T., Wang, T., Zhao, S.J., Yang, K., Chen, X.Q., Zheng, C.H., 2014. Vaspin inhibited proinflammatory cytokine induced activation of nuclear factor-kappa B and its downstream molecules in human endothelial EA.hy926 cells. Diabetes Res. Clin. Pract. 103, 482-488.

[25] Phalitakul, S., Okada, M., Hara, Y., Yamawaki, H., 2013. Vaspin prevents methylglyoxal-induced apoptosis in human vascular endothelial cells by inhibiting reactive oxygen species generation. Acta Physiol. 209, 212-219.

[26] Huh, J.Y., Park, Y.J., Ham, M., Kim, J.B., 2014. Crosstalk between Adipocytes and Immune Cells in Adipose Tissue Inflammation and Metabolic Dysregulation in Obesity. Mol. Cells. 37, 365-371.

[27] Chawla, A., Nguyen, K.D., Goh, Y.P.S., 2011. Macrophage-mediated inflammation in metabolic disease. Nat. Rev. Immunol. 11, 738-749.

[28] Heiker, J.T., 2014. Vaspin (serpinA12) in obesity, insulin resistance, and inflammation. J. Pep. Sci. 20, 299-306.

[29] Phalitakul, S., Okada, M., Hara, Y., Yamawaki, H., 2011. Vaspin prevents TNF-alphainduced intracellular adhesion molecule-1 via inhibiting reactive oxygen species-dependent NF-kappa B and PKC theta activation in cultured rat vascular smooth muscle cells. Pharmacol. Res. 64, 493-500.

[30] Boden, G., 1997. Role of fatty acids in the pathogenesis of insulin resistance and NIDDM. Diabetes. 46, 3-10.

[31] Sinor, A.D., Lillien, L., 2004. Akt-1 expression level regulates CNS precursors. J. Neurosci. 24, 8531-8541. 
[32] Cheatham, B., Vlahos, C.J., Cheatham, L., Wang, L., Blenis, J., Kahn, C.R., 1994. Phosphatidylinositol 3-Kinase Activation Is Required for Insulin Stimulation of Pp70 S6 Kinase, DNA-Synthesis, and Glucose-Transporter Translocation. Mol. Cell. Biol. 14, 49024911.

[33] Copps, K.D., White, M.F., 2012. Regulation of insulin sensitivity by serine/threonine phosphorylation of insulin receptor substrate proteins IRS1 and IRS2. Diabetologia. 55, 25652582 .

[34] Zick, Y., 2005. Ser/Thr phosphorylation of IRS proteins: a molecular basis for insulin resistance. Sci. STKE. 2005, 268, pe4.

[35] Guo, S., 2013. Molecular Basis of Insulin Resistance: The Role of IRS and Foxo1 in the Control of Diabetes Mellitus and Its Complications. Drug Discov. Today Dis. Mech. 10, 27-33.

[36] Wang, Y.M., Wang, W.P., Wang, L.P., Lu, Q.H., Zhou, X.H., 2010. Calorie control increased vaspin levels of serum and periepididymal adipose tissue in diet-induced obese rats in association with serum free fatty acid and tumor necrosis factor alpha. Chin. Med. J. 123, 936-941.

[37] Weiner, J., Rohde, K., Krause, K., Zieger, K., Klöting, N., Kralisch, S., Kovacs, P., Stumvoll, M., Blüher, M., Böttcher, Y., Heiker, J.T., 2017. Brown adipose tissue (BAT) specific vaspin expression is increased after obesogenic diets and cold exposure and linked to acute changes in DNA-methylation. Mol. Metab. 6, 482-493.

[38] Chen, M.W., Deng, D.T., Fang, Z.H., Xu, M., Hu, H.L., Luo, L., Wang, Y.M., 2014. Fenofibrate increases serum vaspin by upregulating its expression in adipose tissue. Endocrine. $45,409-421$.

[39] Kassotis, C.D., Masse, L., Kim, S., Schlezinger, J.J., Webster, T.F., Stapleton, H.M., 2017. Characterization of Adipogenic Chemicals in Three Different Cell Culture Systems: Implications for Reproducibility Based on Cell Source and Handling. Sci. Rep. 7, 42104.

[40] Mohamed-Ali, V., Goodrick, S., Rawesh, A., Katz, D.R., Miles, J.M., Yudkin, J.S., Klein, S., Coppack, S.W., 1997. Subcutaneous adipose tissue releases interleukin-6, but not tumor necrosis factor-alpha, in vivo. J. Clin. Endocrinol. Metab. 82, 4196-4200.

[41] NylanderLundqvist, E., Egelrud, T., 1997. Formation of active IL-1 beta from pro-IL-1 beta catalyzed by stratum corneum chymotryptic enzyme in vitro. Acta Derm. Venereol. 77, 203-206.

[42] Schultz, S., Saalbach, A., Heiker, J.T., Meier, R., Zellmann, T., Simon, J.C., BeckSickinger, A.G., 2013. Proteolytic activation of prochemerin by kallikrein 7 breaks an ionic linkage and results in C-terminal rearrangement. Biochem. J. 452, 271-280.

[43] Yu, Y.J., Prassas, I., Dimitromanolakis, A., Diamandis, E.P., 2015. Novel Biological Substrates of Human Kallikrein 7 Identified through Degradomics. J. Biol. Chem. 290, 1776217775.

[44] Ramani, V.C., Kaushal, G.P., Haun, R.S., 2011. Proteolytic action of kallikrein-related peptidase 7 produces unique active matrix metalloproteinase-9 lacking the C-terminal hemopexin domains. BBA-Mol. Cell Res. 1813, 1525-1531. 


\section{Figures}

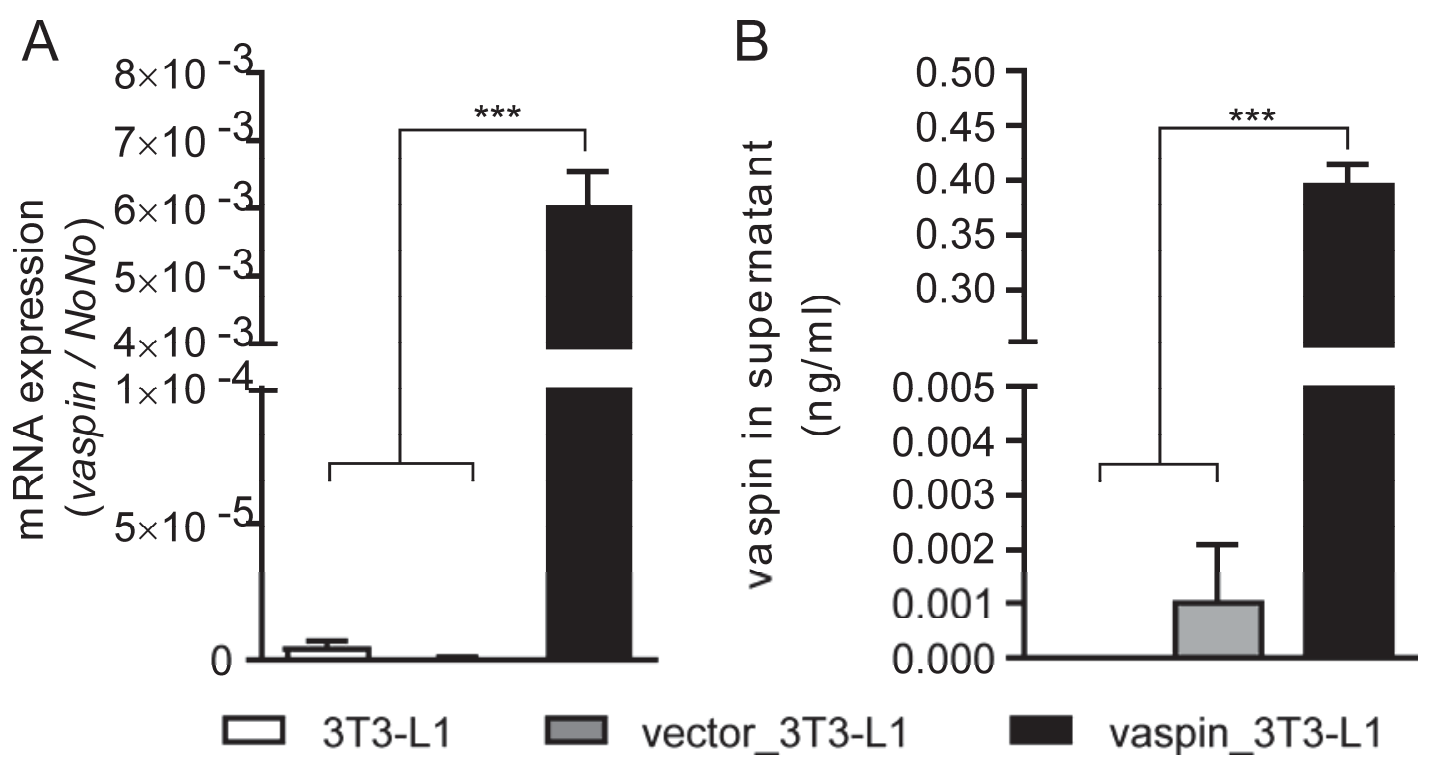

Figure 1. Vaspin expression in 3T3-L1 cells and stably transfected cell lines. (A) Vaspin mRNA expression after full differentiation (day 10) in native 3T3-L1 as well as stably transfected cells. (B) Vaspin secretion was measured in the supernatants of terminally differentiated (day 10) 3T3-L1 cells and stably transfected 3T3-L1 cells. Vector_3T3-L1 correspond to cells transfected with empty pcDNA3.1 vector, vaspin_3T3-L1 with the corresponding plasmid containing the sequence for human vaspin. Data is of three independent experiments in duplicates and all values are shown as mean $\pm \operatorname{SEM}(* * * p<0.001$, One-way ANOVA). 

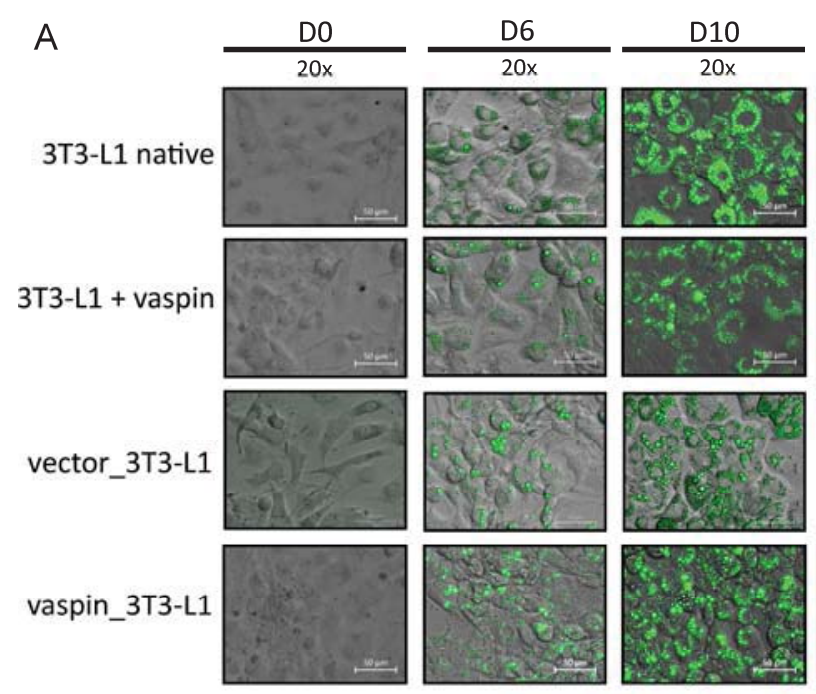

B
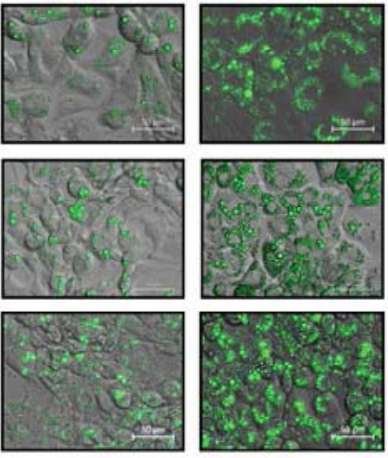

Intracellular Lipid Accumulation

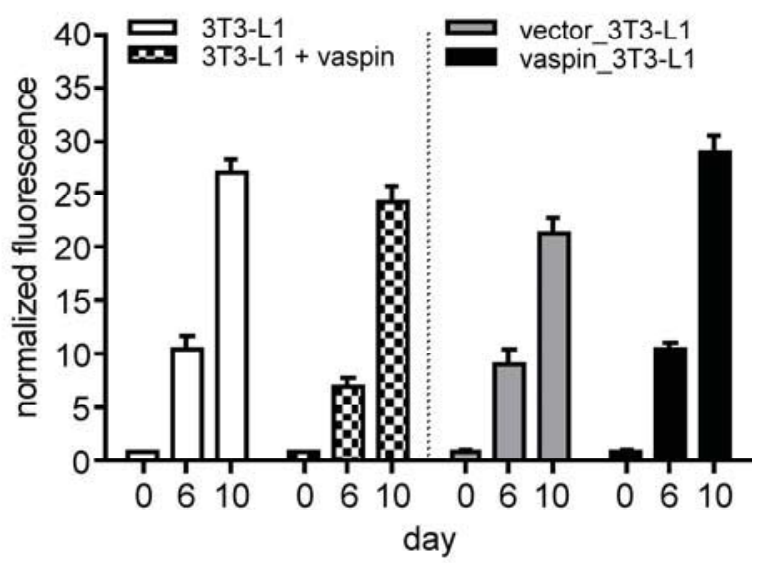

C
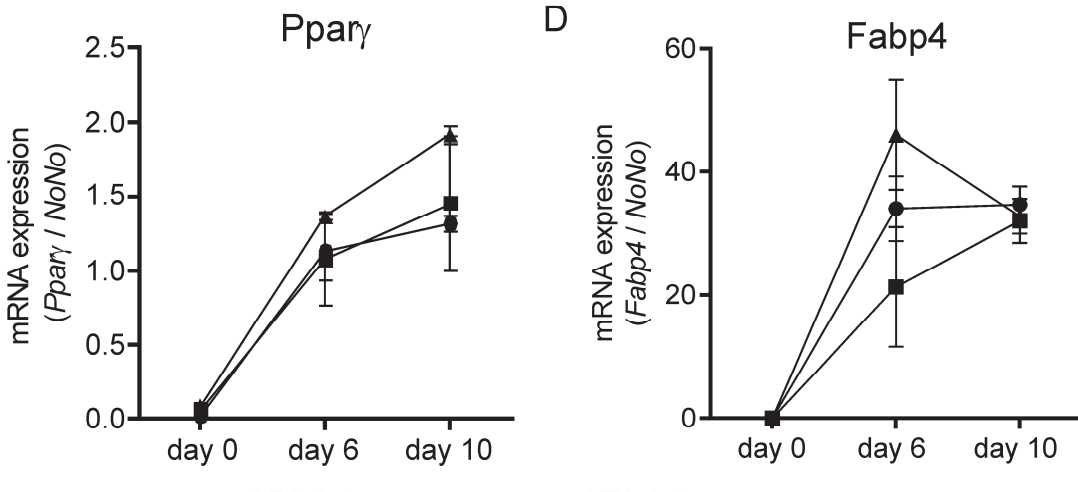

- 3 TT3-L1 $\_$vector_3T3-L1

vaspin_3T3-L1

Figure 2. Differentiation, lipid accumulation and marker gene expression during adipogenesis of native and vaspin treated 3T3-L1 and vaspin expressing vaspin cell clones.

(A) Fluorescence microscopy of native and vaspin $(200 \mathrm{ng} / \mathrm{ml})$ treated 3T3-L1 as well as stably transfected cell clones (vector_3T3-L1, vaspin_3T3-L1). Lipid droplets are stained with lipophilic AdipoRed reagent. Pictures at day 0, day 6 and day 10 are representative of three passages of all cells. (B) Quantification of lipid accumulation using the AdipoRed assay demonstrates that exogenous vaspin $(200 \mathrm{ng} / \mathrm{ml})$ treatment and induction of endogenous vaspin expression did not alter lipid accumulation in 3T3-L1 cells. Also control cells (vector_3T3-L1) differentiate like native 3T3-L1 cells. (C, D) Selected marker genes of adipogenesis, such as Ppary (C) and Fabp4 (D) are increased during differentiation for native as well as stably transfected cell clones. Data is of three independent experiments in duplicates or triplicates and all values are shown as mean \pm SEM. 


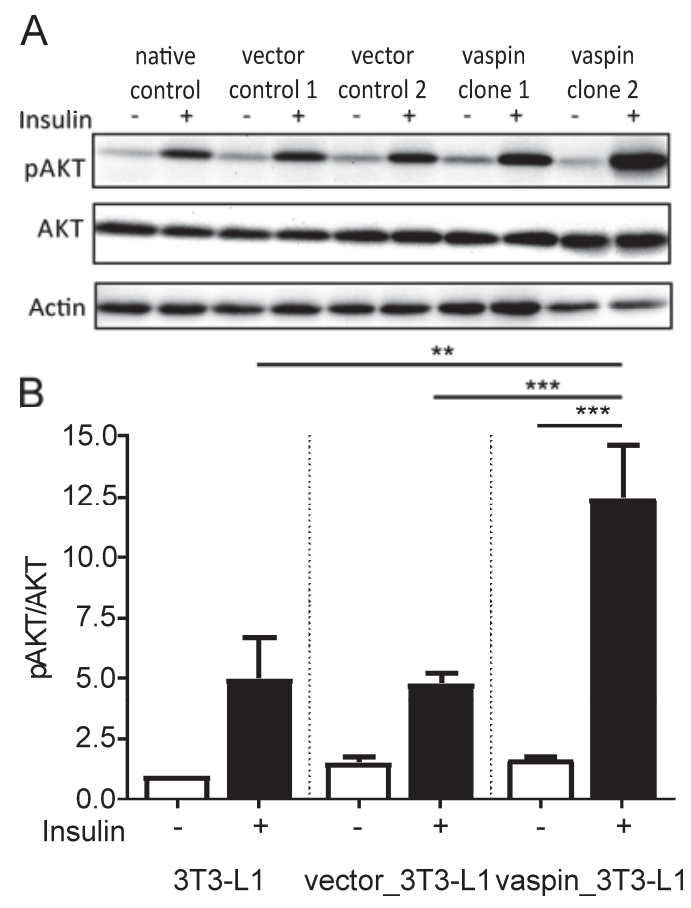

Figure 3. Endogenous vaspin expression increases insulin-induced AKT phosphorylation in differentiated 3T3-L1 adipocytes. (A) Fully differentiated native, vector_3T3-L1 or vaspin_3T3-L1 cells were stimulated with insulin $(100 \mu \mathrm{M}$ for $15 \mathrm{~min})$ and intracellular AKT and AKT phosphorylation (Ser473) were measured in Western blot analyses. (B) Densitometric quantification demonstrated that basal AKT phosphorylation was unaffected by expression of vaspin, but revealed a significant increase in insulin-induced AKT phosphorylation in vaspin expressing 3T3-L1 clones. Data is of three independent experiments in duplicates and all values are shown as mean \pm SEM. $(* * p<0.01 ; * * * p<0.001$; One-way ANOVA). 

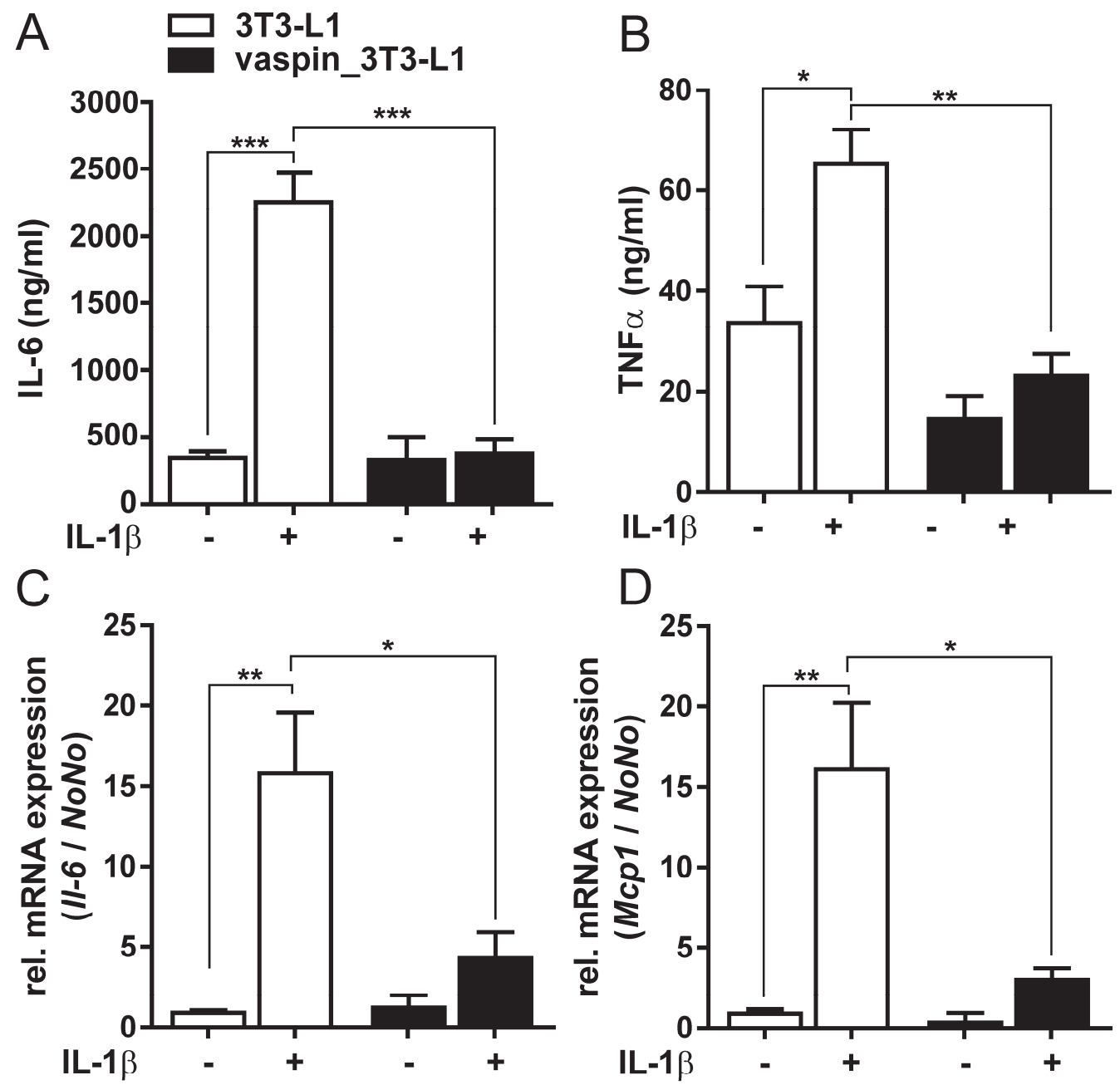

Figure 4. Vaspin inhibits IL-1ß-induced expression and secretion of pro-inflammatory cytokines in differentiated 3T3-L1. Fully differentiated native or vaspin_3T3-L1 cells were stimulated with IL-1 $\beta$ (15 min) and mRNA expression and protein secretion of proinflammatory IL-6 (A, C), TNF $\alpha$ (B) and MCP1 (D) was measured. Induction of endogenous vaspin expression blunted IL-1 $\beta$-induced expression and secretion of pro-inflammatory cytokines. Data is of three independent experiments in duplicates and all values are shown as mean $\pm \operatorname{SEM}\left(* \mathrm{p}<0.05,{ }^{*} \mathrm{p}<0.01,{ }^{* * *} \mathrm{p}<0.001\right.$; One-way ANOVA $)$. 


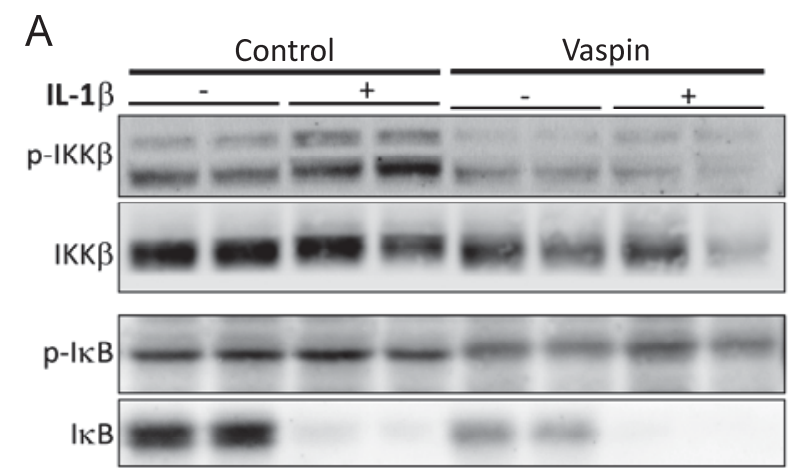

B
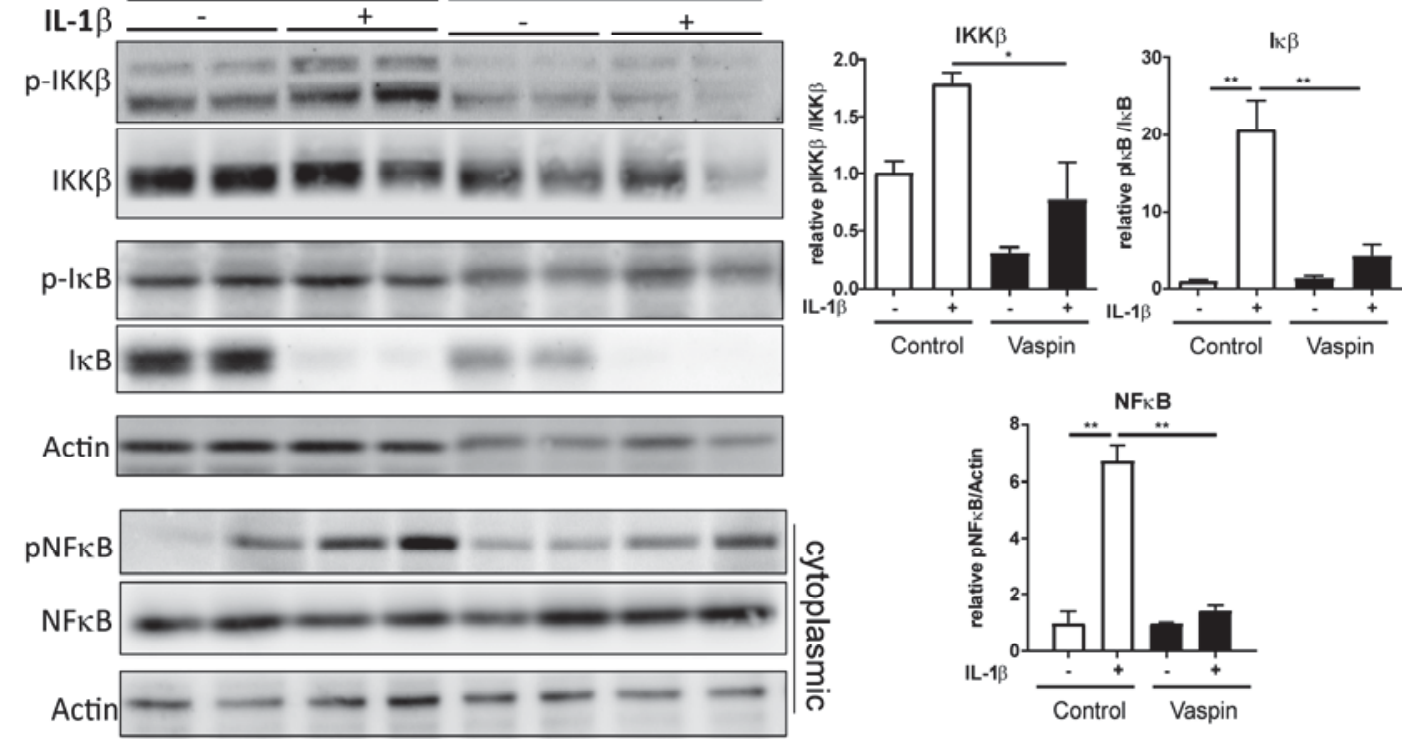

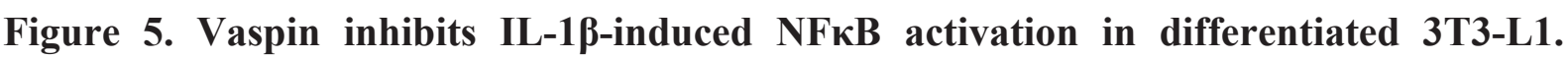
(A) IL-1 $\beta$-induced phosphorylation of IKK $\beta$ (Ser176/S180), IкB (Ser32) and NFkB (Ser536) and corresponding total protein was analyzed by Western blot in native 3T3-L1 cells treated with or without $200 \mathrm{ng} / \mathrm{ml}$ vaspin during adipocyte differentiation (day 2-10). (B) Relative

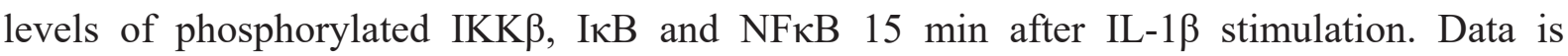
representative of three independent experiments in duplicates and all values are shown as mean $\pm \operatorname{SEM}(* \mathrm{p}<0.05, * * \mathrm{p}<0.01$, One-way ANOVA $)$. 